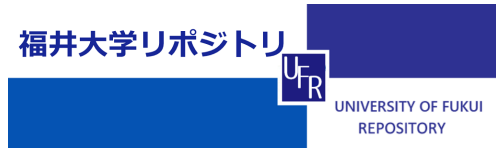

A Scheme for Col lecting Anonymous Dat a

\begin{tabular}{|l|l|}
\hline $\begin{array}{l}\text { j our nal or } \\
\text { publ i cat i on } \mathrm{t} \text { i t I e }\end{array}$ & I EEE I Cl T 2012 \\
\hline year & 2013 - 02 \\
\hline URL & ht t p: //hdl . handl e. net /10098/7280 \\
\hline
\end{tabular}




\title{
A Scheme for Collecting Anonymous Data
}

\author{
Shinsuke Tamura, Shuji Taniguchi \\ Graduate School of Engineering \\ University of Fukui \\ Fukui, Japan \\ tamura@u-fukui.ac.jp
}

\begin{abstract}
This paper proposes a scheme for calculating aggregate values of data owned by anonymous entities. Linear mix-nets, an unknown unique number generator, and anonymous tag based credentials efficiently conceal not only identities of data owners but also linkages between data owned by same entities. Then, the scheme enables quick introduction of advancing information technologies to industrial applications while ensuring confidentiality of sensitive data, e.g. a machine maintenance company can monitor states of machines remotely without knowing secrets of machine owners, companies can outsource even their sensitive tasks without worrying about leaks of their secrets. The scheme is also applicable to tasks in egovernance systems such as tax-collections where privacies of individuals must be preserved.
\end{abstract}

Index Terms - remote maintenance, e-governance, cloud computing, linear mix-net, anonymous tag, anonymous credential.

\section{INTRODUCTION}

Let us assume a situation where a remote maintenance company calculates the sum of data about machines at factories of a manufacturing company. Where, the sum is calculated for some reasons, but confidentiality of the manufacturing company must be ensured. Therefore, the remote maintenance company must calculate the sum without knowing owners of individual data. Because a set of data owned by a same company include many clues to identify the company, it must calculate the sum without knowing linkages between data owned by same companies either. Same situations exist also in cloud computing and e-governance systems, e.g. a company that carries out its tasks by using cloud computing resources may want to conceal its sensitive data even from mangers of the cloud computing system, and citizens in e-governance systems may not want governments to know their total properties or to link their individual properties.

The anonymous data collection scheme proposed in this paper exploits linear mix-nets, an unknown unique number generator, and anonymous tag based credentials to cope with the above situations securely and efficiently. Namely, one of the linear mix-nets is used to encrypt individual data owned by anonymous entity $P$ so that no one except $P$ can know correspondences between individual data and $P$, nevertheless by using the unknown unique number generator an authority (e.g. a remote maintenance company) can collect encrypted data of $P$, and the other linear mix-net enables the authority to calculate the sum of data owned by $P$ from the collected encrypted forms so that $P$ can take required actions, e.g. replace old machines with new ones or pay fees for services provided by the maintenance company. Finally, anonymous tag based credentials enable the authority to identify entities that do not complete the required actions.

Where, although various mechanisms for handling anonymous information have been developed already, they are not efficient enough for data collection systems. For example, it is possible to calculate sums of data without knowing their individual values or their owners when widely used mix-nets [2][3] and encryption schemes such as RSA or ElGamal are combined. Namely, mix-nets conceal linkages between encrypted and decrypted forms of data (this means the owner of data can conceal the correspondence between itself and its data), also RSA and ElGamal enable the authority to calculate the sum of data from their encrypted forms (this means the authority can calculate the sum without knowing individual values). However, mix-nets, RSA and ElGamal are designed to handle data represented as integers, and they are too inefficient to process real numbers that appear in many important applications. Different from usual mix-nets, linear mix-nets in the proposed scheme handle real numbers totally in the same way as integers.

About identifications of entities that do not complete required actions (in the remainder, these entities are called dishonest entities), zero knowledge proof (ZKP) based anonymous credentials are widely used and they satisfactory identify dishonest entities while preserving privacies of honest entities. However, ZKPs are not practical, i.e. they require numbers of challenges and responses [4][5]. Credentials based on anonymous tags require only limited number of challenges and responses and reduce computation volumes drastically.

Then, the proposed scheme enables highly efficient calculation of aggregate values while maintaining confidentialities of individual data and linkages between the data and their owners. In the remainder, it is assumed that the authority calculates sums of data. But slight modifications enable also calculation of polynomial functions of data.

\section{SYSTEM CONFIGURATION}

Fig. 1 shows 6 parts of the proposed system, i.e. they are member registration, distributed data storage, the 1 st and the 2nd linear mix-nets, bulletin board (BB), and dishonest entity identification parts. First of all, the member registration part registers entity $P$ as a member of the system, i.e. authority $S$ 
gives anonymous credential $\mathrm{T}_{\mathrm{P}}(0)$ to $P$ if it is eligible. At the same time $S$ defines a unique random number $\mathrm{N}_{P}$ to give it to $P$, where, $\mathrm{N}_{\mathrm{P}}$ is encrypted by multiple independent sub-authorities so that no one except $P$ can know its value. Then, $P$ stores its individual data $\mathrm{D}_{\mathrm{P}}(1), \mathrm{D}_{\mathrm{P}}(2),---, \mathrm{D}_{\mathrm{P}}(\mathrm{Q})$ in the distributed data storage together with the credential and the encrypted unique random number without disclosing its identity. In detail, for each data item $\mathrm{D}_{\mathrm{P}}(\mathrm{q}), P$ transforms credential $\mathrm{T}_{\mathrm{P}}(0)$ to $\mathrm{T}_{\mathrm{P}}(\mathrm{q})$ to disable others to link $D_{P}(q)$ to other data item $D_{P}\left(q_{*}\right)(q \neq q *)$, proves its eligibility by showing $T_{P}(q)$, after that stores $D_{P}(q)$ together with its encrypted form $\mathrm{E}^{*}\left(\mathrm{k}_{*}, \mathrm{D}_{\mathrm{P}}(\mathrm{q})\right)$, where $\mathrm{k} *$ and $\mathrm{g}_{*}$ below represent secret encryption keys of multiple independent sub-authorities as shown later. Also, $P$ attaches credential $T_{P}(q)$ and unique random number $\mathrm{N}_{\mathrm{P}}$ in form $\mathrm{E}\left(\mathrm{g}_{*}, \mathrm{~N}_{\mathrm{P}}(\mathrm{q}), \mathrm{r}_{\mathrm{Pq}}\right)$. Here $r_{P q}$ is a random integer that makes the encryption result unique, i.e. although both $E\left(g_{*}, N_{P}, r_{P q}\right)$ and $E\left(g_{*}, N_{P}, r_{P j}\right)$ are decrypted to $\mathrm{N}_{\mathrm{P}}$, entities other than $P$ cannot know that $\mathrm{E}\left(\mathrm{g}_{*}, \mathrm{~N}_{\mathrm{P}}, \mathrm{r}_{\mathrm{Pq}}\right)$ and $\mathrm{E}\left(\mathrm{g}_{*}, \mathrm{~N}_{\mathrm{P}}, \mathrm{r}_{\mathrm{Pj}}\right)$ are the encrypted forms of the same number. Then, no one other than $P$ can link $\mathrm{D}_{\mathrm{P}}(1),---, \mathrm{D}_{\mathrm{P}}(\mathrm{Q})$.

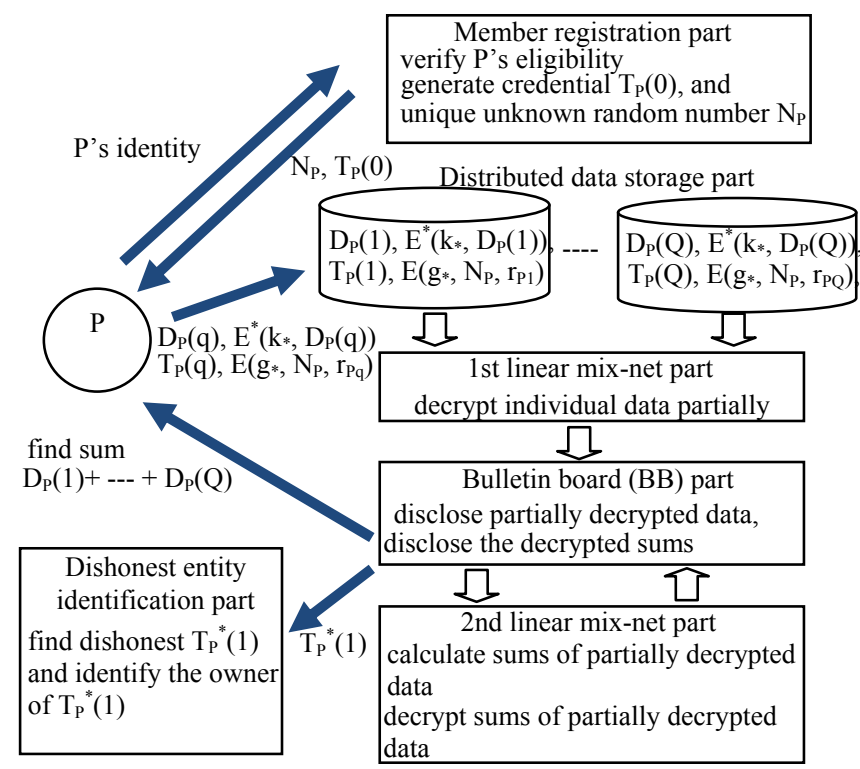

Fig. 1. Configuration of the anonymous data collection system

After that, each triple $\left\{\mathrm{E}^{*}\left(\mathrm{k}_{*}, \mathrm{D}_{\mathrm{P}}(\mathrm{q})\right), \mathrm{T}_{\mathrm{P}}(\mathrm{q}), \mathrm{E}\left(\mathrm{g}_{*}, \mathrm{~N}_{\mathrm{P}}, \mathrm{r}_{\mathrm{Pq}}\right)\right\}$ in the distributed data storage is decrypted (actually $T_{P}(q)$ is encrypted) by the 1st linear mix-net to be put in the $\mathrm{BB}$ while being shuffled with other triples. Here, although $\mathrm{E}\left(\mathrm{g}_{*}, \mathrm{~N}_{\mathrm{P}}, \mathrm{r}_{\mathrm{Pq}}\right)$ is decrypted to $\mathrm{N}_{\mathrm{P}}$ and $\mathrm{T}_{\mathrm{P}}(\mathrm{q})$ is encrypted to $\mathrm{T}_{\mathrm{P}}{ }^{*}(\mathrm{q}), \mathrm{E}^{*}(\mathrm{k} *$ $\left.D_{P}(q)\right)$ is decrypted only partially into $E^{*}\left(k_{Z^{*}}, D_{P}(q)\right)$, therefore anyone cannot know the correspondence between $\mathrm{E}^{*}\left(\mathrm{k}_{\mathrm{Z}^{*}}\right.$, $\mathrm{D}_{\mathrm{P}}(\mathrm{q})$ ) and $\mathrm{D}_{\mathrm{P}}(\mathrm{q})$. But because all data owned by $P$ are accompanied by $\mathrm{N}_{\mathrm{P}}, \mathrm{S}$ can collect $P$ 's data $\mathrm{E}^{*}\left(\mathrm{k}_{\mathrm{Z}^{*}}, \mathrm{D}_{\mathrm{P}}(1)\right),---$, $\mathrm{E}^{*}\left(\mathrm{k}_{\mathrm{Z}^{*}}, \mathrm{D}_{\mathrm{P}}(\mathrm{Q})\right)$ to calculate their sum and attach $\mathrm{N}_{\mathrm{P}}$ and $\mathrm{T}_{\mathrm{P}}{ }^{*}(1)$ to the sum. In addition, $\mathrm{E}^{*}\left(\mathrm{k}_{\mathrm{Z}^{*}}, x\right)$ is configured as an additive encryption function, therefore the 2nd linear mix-net can decrypt the sum to $\mathrm{D}_{\mathrm{P}}(1)+\mathrm{D}_{\mathrm{P}}(2)+$--- $+\mathrm{D}_{\mathrm{P}}(\mathrm{M})$ to be disclosed in the $\mathrm{BB}$ together with $\mathrm{N}_{\mathrm{P}}$ and $\mathrm{T}_{\mathrm{P}}{ }^{*}(1)$.

As a consequence, $P$ can identify the sum of its data in the $\mathrm{BB}$ based on $\mathrm{N}_{P}\left(\mathrm{P}\right.$ knows $\mathrm{N}_{\mathrm{P}}$ ) and can begin the required actions about the sum, but entities other than $P$ cannot know the correspondence between $P$ and the sum, because $N_{P}$ is known only to $\mathrm{P}$. Nevertheless, credential $\mathrm{T}_{\mathrm{P}}{ }^{*}(1)$ attached to the sum enables the dishonest entity identification part to identify $P$ when it does not complete the required actions without knowing any secret of honest members. Namely as discussed later, used seal of credential $\mathrm{T}_{\mathrm{P}}{ }^{*}(1)$ forces $P$ to disclose its identity. Then, if $P$ is a manufacturing company and each $D_{P}(q)$ is the fee for maintaining machine $\mathrm{M}_{\mathrm{q}}$ owned by $P$ for example, remote maintenance company $S$ can force $P$ to honestly pay fees for services it provided for machines owned by $P$, on the other hand, $P$ can conceal its individual machines and their hours of operations from $S$.

\section{UNKNOWN UNIQUE NUMBER GENERATOR}

To generate unique secret integer $\mathrm{N}_{\mathrm{P}}$ authority $S$ is constituted by multiple mutually independent sub-authorities $S_{1}$, $---, S_{\mathrm{Z}}, S_{\mathrm{Z}+1},---, S_{\mathrm{J}}$, and member $P$ and $S_{\mathrm{Z}+1},---, S_{\mathrm{J}}$ behave as follows [8]. Firstly, each authority $S_{\mathrm{h}}$ generates its secret integer $\mathrm{p}(\mathrm{h})$, and informs authority $S$ (representative of $S_{1}$, ---, $S_{\mathrm{J}}$ ) of $\mathrm{C}^{\mathrm{p}(\mathrm{h})}{ }_{\bmod \mathrm{B}}$. Where B is a publicly known appropriate large integer, therefore, it is practically impossible for anyone other than $S_{\mathrm{h}}$ to know $\mathrm{p}(\mathrm{h})$ from $\mathrm{C}^{\mathrm{p}(\mathrm{h})} \bmod \mathrm{B}$, i.e. calculating $\mathrm{p}(\mathrm{h})$ from $\mathrm{C}^{\mathrm{p}(\mathrm{h})}{ }_{\bmod \mathrm{B}}$ is a discrete logarithm problem. After receiving $\mathrm{C}^{\mathrm{p}(\mathrm{h})}{ }_{\bmod }$ B from each $S_{\mathrm{h}}, S$ calculates $\mathrm{C}^{\mathrm{NP}}=\mathrm{C}^{\mathrm{p}(\mathrm{Z}+1)} \mathrm{C}^{\mathrm{p}(\mathrm{Z}+2)}---\mathrm{C}^{\mathrm{p}(\mathrm{J})}=$ $\mathrm{C}^{\mathrm{p}(\mathrm{Z}+1)+\mathrm{p}(\mathrm{Z}+2)+\cdots+\mathrm{p}(\mathrm{J})}$ (in the followings notation $\bmod \mathrm{B}$ is omitted when confusions can be avoided) and asks each $S_{\mathrm{h}}$ to disclose $\mathrm{p}(\mathrm{h})$ to $P$ when $\mathrm{C}^{\mathrm{NP}}$ did not appear before. Then, $P$ calculates $\mathrm{N}_{\mathrm{P}}=\mathrm{p}(\mathrm{Z}+1)+\mathrm{p}(\mathrm{Z}+2)+---+\mathrm{p}(\mathrm{J})$ and finally encrypts it to $\mathrm{E}\left(\mathrm{g}_{*}\right.$, $\left.\mathrm{N}_{\mathrm{P}}, \mathrm{r}_{\mathrm{P} 1}\right), \mathrm{E}\left(\mathrm{g}_{*}, \mathrm{~N}_{\mathrm{P}}, \mathrm{r}_{\mathrm{P} 2}\right),---, \mathrm{E}\left(\mathrm{g}_{*}, \mathrm{~N}_{\mathrm{P}}, \mathrm{r}_{\mathrm{PQ}}\right)$ by using public encryption keys $\mathrm{g}_{\mathrm{Z}+1},---, \mathrm{g}_{\mathrm{J}}$ of $S_{\mathrm{Z}+1},---, S_{\mathrm{J}}$. Where, $\mathrm{E}\left(\mathrm{g}_{*}, \mathrm{~N}_{\mathrm{P}}\right.$, $\left.\mathrm{r}_{\mathrm{Pq}}\right)=\mathrm{E}\left(\mathrm{g}_{\mathrm{J}}, \mathrm{E}\left(\mathrm{g}_{\mathrm{J}-1},---\mathrm{E}\left(\mathrm{g}_{\mathrm{Z}+1}, \mathrm{~N}_{\mathrm{P}}, \mathrm{r}_{\mathrm{Pq}}\right)---\right)\right)$, and $\mathrm{r}_{\mathrm{Pq}}$ is $P$ 's secret integer that makes encryption function $\mathrm{E}\left(\mathrm{g}_{*}, x\right)$ probabilistic as mentioned before.

In the above, each $S_{\mathrm{h}}$ does not know $\mathrm{p}(\mathrm{j})$ generated by other authority $S_{\mathrm{j}}$, therefore no single entity except $P$ can know $\mathrm{N}_{\mathrm{P}}$. Because $P$ defines $r_{P 1}, r_{P 2},---, r_{P Q}$ independently, no one except $P$ can know the linkage between $\mathrm{E}\left(\mathrm{g}_{*}, \mathrm{~N}_{\mathrm{P}}, \mathrm{r}_{\mathrm{Ph}}\right)$ and $\mathrm{E}\left(\mathrm{g}_{*}, \mathrm{~N}_{\mathrm{P}}, \mathrm{r}_{\mathrm{Pj}}\right)$ when $\mathrm{h} \neq \mathrm{j}$ either. Also, apparently uniqueness of $\mathrm{N}_{P}$ is ensured, and at the same time confidentiality of $\mathrm{N}_{P}$ is maintained even when same value $\mathrm{C}^{\mathrm{NP}}$ appears repeatedly, because each $S_{\mathrm{h}}$ knows only $\mathrm{p}(\mathrm{h})$.

\section{LINEAR MIX-NET}

A linear mix-net is a mix-net, in which linear equation based encryption functions are exploited. Namely as shown in Fig. 2, authorities $S_{\mathrm{J}},---, S_{\mathrm{Z}+1}, S_{\mathrm{Z}},---, S_{1}$ in the 1 st and the 2 nd linear mix-nets decrypt $\mathrm{E}^{*}\left(\mathrm{k}_{*}, \mathrm{D}_{\mathrm{P}}(\mathrm{q})\right)=\mathrm{E}^{*}\left(\mathrm{k}_{\mathrm{J}}, \mathrm{E}^{*}\left(\mathrm{k}_{\mathrm{J}-1},---\mathrm{E}^{*}\left(\mathrm{k}_{1}\right.\right.\right.$, $\left.\mathrm{D}_{\mathrm{P}}(\mathrm{q})\right)$---)), member $P$ 's data $\mathrm{D}_{\mathrm{P}}(\mathrm{q})$ repeatedly encrypted by secret keys $\mathrm{k}_{1}, \mathrm{k}_{2},---, \mathrm{k}_{\mathrm{J}}$ of $\mathrm{S}_{1}, S_{2},---, S_{\mathrm{J}}$, into $\mathrm{D}_{\mathrm{P}}(\mathrm{q})$ while shuffling individual decryption results with those owned by other members (actually $S_{Z},---, S_{1}$ in the 2nd linear mix-net do not need to shuffle their decryption results), therefore no single entity other than $P$ can identify the correspondence between $E^{*}\left(k_{*}, D_{P}(q)\right)$ and $E^{*}\left(k_{h^{*}}, D_{P}(q)\right)=E^{*}\left(k_{h}, E^{*}\left(k_{h-1},---E^{*}\left(k_{1}\right.\right.\right.$, $\left.\mathrm{D}_{\mathrm{P}}(\mathrm{q})\right)$---)) for any $\mathrm{h}\left(\right.$ i.e. $\mathrm{D}_{\mathrm{P}}(\mathrm{q})$ and $\mathrm{E}^{*}\left(\mathrm{k}_{\mathrm{h}^{*}}, \mathrm{D}_{\mathrm{P}}(\mathrm{q})\right)$. 
Here, one of distinctive features of each encryption function $E^{*}\left(k_{h}, x\right)$ is it can handle real numbers as same as integers, therefore, member $P$ and authorities can encrypt and decrypt their relevant data efficiently even the data are real numbers. As another important feature, $\mathrm{E}^{*}\left(\mathrm{k}_{\mathrm{h}}, x\right)$ is additive, i.e. relation $a \mathrm{E}^{*}\left(\mathrm{k}_{\mathrm{h}}, x\right)+b \mathrm{E}^{*}\left(\mathrm{k}_{\mathrm{h}}, y\right)=\mathrm{E}^{*}\left(\mathrm{k}_{\mathrm{h}}, a x+b y\right)$ holds for any real numbers $a$ and $b$. Therefore, when the 1st linear mix-net $S_{\mathrm{J}}$, ---, $S_{\mathrm{Z}+1}$ decrypts each $\mathrm{E}^{*}\left(\mathrm{k}_{*}, \mathrm{D}_{\mathrm{P}}(\mathrm{q})\right)$ to $\mathrm{E}^{*}\left(\mathrm{k}_{\mathrm{Z}^{*}}, \mathrm{D}_{\mathrm{P}}(\mathrm{q})\right)$ and calculates sum $E^{*}\left(k_{Z^{*}}, D_{P}(1)\right)+---+E^{*}\left(k_{Z^{*}}, D_{P}(Q)\right)$, the sum coincides with $\mathrm{E}^{*}\left(\mathrm{k}_{\mathrm{Z}^{*}}, \mathrm{D}_{\mathrm{P}}(1)+---+\mathrm{D}_{\mathrm{P}}(\mathrm{Q})\right)$ as shown at the bottom of Fig. 2 , and Total $_{\mathrm{P}}=\mathrm{D}_{\mathrm{P}}(1)+$--- $+\mathrm{D}_{\mathrm{P}}(\mathrm{Q})$ is revealed when $\mathrm{E}^{*}\left(\mathrm{k}_{\mathrm{Z}^{*}}\right.$, $\left.\mathrm{D}_{\mathrm{P}}(1)+---+\mathrm{D}_{\mathrm{P}}(\mathrm{Q})\right)$ is decrypted by the 2 nd linear mix-net $S_{\mathrm{Z}}$, ---, $S_{1}$. Then, $S$ can know that the sum of data owned by some entity is Total $_{P}$, but no one except $P$ can know the linkage between $\mathrm{D}_{\mathrm{P}}(1)$, ---, $\mathrm{D}_{\mathrm{P}}(\mathrm{Q})$ or the correspondence between $P$ and Total

About Fig. 2, it must be noted that $P$ encrypts $\mathrm{N}_{\mathrm{P}}$ by public encryption keys of only authorities $S_{\mathrm{Z}+1},---, S_{\mathrm{J}}$. This means all decryption results $\mathrm{E}^{*}\left(\mathrm{k}_{\mathrm{Z}^{*}}, \mathrm{D}_{\mathrm{P}}(1)\right), \quad---, \quad \mathrm{E}^{*}\left(\mathrm{k}_{\mathrm{Z}^{*}}, \mathrm{D}_{\mathrm{P}}(\mathrm{Q})\right)$ corresponding to $P$ are accompanied by same integer $N_{P}$, therefore, $S_{\mathrm{Z}_{+1}}$ can collect $\mathrm{E}^{*}\left(\mathrm{k}_{\mathrm{Z}^{*}}, \mathrm{D}_{\mathrm{P}}(1)\right),---, \mathrm{E}^{*}\left(\mathrm{k}_{\mathrm{Z}^{*}}, \mathrm{D}_{\mathrm{P}}(\mathrm{Q})\right)$ to calculate their sum $\mathrm{E}^{*}\left(\mathrm{k}_{\mathrm{Z}^{*}}, \mathrm{D}_{\mathrm{P}}(1)+---+\mathrm{D}_{\mathrm{P}}(\mathrm{Q})\right)$.

$\mathrm{E}^{*}\left(\mathrm{k}_{\mathrm{h}}, x\right)$ with the above features can be constructed as below. Namely, $\mathrm{E}^{*}\left(\mathrm{k}_{\mathrm{h}}, x\right)$ transforms $x$ to vector $\left\{\mathrm{m}_{1}, \mathrm{~m}_{2},---\right.$, $\left.\mathrm{m}_{\mathrm{G}}\right\}$ that is calculated as in Eq. 1, where coefficient matrix $\left\{\mathrm{k}(\mathrm{h})_{\mathrm{st}}\right\}$ constitutes secret key $\mathrm{k}_{\mathrm{h}}$ of $S_{\mathrm{h}}$, and $\mathrm{u}_{1}, \mathrm{u}_{2},---, \mathrm{u}_{\mathrm{G}}$ are real numbers secrets of $S_{\mathrm{h}}$ [6][8]. Then, entities that do not know matrix $\left\{\mathrm{k}(\mathrm{h})_{\mathrm{st}}\right\}$ cannot calculate $x$ from $\left\{\mathrm{m}_{1}, \mathrm{~m}_{2},---, \mathrm{m}_{\mathrm{G}}\right\}$, but $S_{\mathrm{h}}$ that knows $\left\{\mathrm{k}(\mathrm{h})_{\text {st }}\right\}$ can solve Eq. 1 to know $x$.

$$
\begin{aligned}
& \mathrm{m}_{1}=\mathrm{k}(\mathrm{h})_{11} x+\mathrm{k}(\mathrm{h})_{12} \mathrm{u}_{1}+---+\mathrm{k}(\mathrm{h})_{1 \mathrm{G}} \mathrm{u}_{\mathrm{G}-1} \\
& \mathrm{~m}_{2}=\mathrm{k}(\mathrm{h})_{21} x+\mathrm{k}(\mathrm{h})_{22} \mathrm{u}_{1}+---+\mathrm{k}(\mathrm{h})_{2 \mathrm{G}} \mathrm{u}_{\mathrm{G}-1}
\end{aligned}
$$

$$
\mathrm{m}_{\mathrm{G}}=\mathrm{k}(\mathrm{h})_{\mathrm{G} 1} x+\mathrm{k}(\mathrm{h})_{\mathrm{G} 2} \mathrm{u}_{1}+---+\mathrm{k}(\mathrm{h})_{\mathrm{GG}} \mathrm{u}_{\mathrm{G}-1}
$$

As widely known, linear equation based encryption functions are weak against plaintext attacks, where an entity illegitimately knows secret keys based on known plain text and their encrypted form pairs (e.g. it is easy to calculate $\left\{\mathrm{k}(\mathrm{h})_{\text {st }}\right\}$ in Eq. 1 when G-mutually independent vectors and their decrypted values are given). But in this scheme, $S_{\mathrm{h}}$ itself that encrypts $x$ decrypts $\left\{\mathrm{m}_{1}, \mathrm{~m}_{2},---, \mathrm{m}_{\mathrm{G}}\right\}$, therefore plain text that includes secret numbers $\mathrm{u}_{1}, \mathrm{u}_{2},---, \mathrm{u}_{\mathrm{G}-1}$ is never disclosed to others. Also, encrypted form of $x$ can be constructed as $\left\{\mathrm{m}_{1}\right.$, $\left.\mathrm{m}_{2}, \mathrm{~d}_{1}, \mathrm{~m}_{3}, \mathrm{~d}_{2},---\right\}$ while being merged with secret dummy elements $\left\{\mathrm{d}_{1},---, \mathrm{d}_{\mathrm{G}^{*}}\right\}$, and $\mathrm{m}_{\mathrm{j}}$ can be represented as the sum of multiple elements $\left\{\mathrm{m}_{\mathrm{j} 1}, \mathrm{~m}_{\mathrm{j} 2},---, \mathrm{m}_{\mathrm{jj}}\right\}$ if necessary, therefore plain text attacks become extremely difficult.

However different from usual mix-nets, encryption key $\mathrm{k}_{\mathrm{h}}$ of $E^{*}\left(\mathrm{k}_{\mathrm{h}}, x\right)$ is a secret of $S_{\mathrm{h}}$, therefore $P$ must ask $S_{1},---, S_{\mathrm{J}}$ to encrypt each $D_{P}(q)$, and as a result, although $P$ is anonymous $S_{\mathrm{h}}$ can know the linkage between $\mathrm{D}_{\mathrm{P}}(\mathrm{q})$ and partially decrypted form $\mathrm{E}^{*}\left(\mathrm{k}_{\mathrm{h}^{*}}, \mathrm{D}_{\mathrm{P}}(\mathrm{q})\right)$, because $S_{\mathrm{h}}$ itself calculates $\mathrm{E}^{*}\left(\mathrm{k}_{\mathrm{h}^{*}}, \mathrm{D}_{\mathrm{P}}(\mathrm{q})\right)$ from $\mathrm{E}^{*}\left(\mathrm{k}_{(\mathrm{h}-1)^{*}}, \mathrm{D}_{\mathrm{P}}(\mathrm{q})\right)$ at a time when $P$ asks authorities to encrypt $\mathrm{D}_{\mathrm{P}}(\mathrm{q})$ to $\mathrm{E}^{*}\left(\mathrm{k}_{*}, \mathrm{D}_{\mathrm{P}}(\mathrm{q})\right)$. To disable $S_{\mathrm{h}}$ to know this linkage, $P$ constructs $\mathrm{E}^{*}\left(\mathrm{k} *, \mathrm{D}_{\mathrm{P}}(\mathrm{q})\right)$ as follows.
As shown in the upper part of Fig.2, firstly $P$ asks $S_{1}$, ---, $S_{\mathrm{J}}$ to repeatedly encrypt $\mathrm{D}_{\mathrm{P}}(\mathrm{q})$ to $\mathrm{E}\left(\mathrm{k}_{*}, \mathrm{D}_{\mathrm{P}}(\mathrm{q})\right)=\mathrm{E}\left(\mathrm{k}_{\mathrm{J}}, \mathrm{E}\left(\mathrm{k}_{\mathrm{J}-1},--\right.\right.$ - $\mathrm{E}\left(\mathrm{k}_{1}, \mathrm{D}_{\mathrm{P}}(\mathrm{q})\right)$----)), where $\mathrm{E}\left(\mathrm{k}_{\mathrm{h}}, \mathrm{D}_{\mathrm{P}}(\mathrm{q})\right)$ is calculated as linear combinations of $\mathrm{D}_{\mathrm{P}}(\mathrm{q})$ and secret random numbers as same as $\mathrm{E}^{*}\left(\mathrm{k}_{\mathrm{h}}, \mathrm{D}_{\mathrm{P}}(\mathrm{q})\right)$ shown in Eq. 1. After that $P$ generates its secret numbers $a_{1 \mathrm{q}}(\mathrm{P}), a_{2 \mathrm{q}}(\mathrm{P}),---, a_{\mathrm{Lq}}(\mathrm{P})$ and calculates $\mathrm{E}^{*}\left(\mathrm{k}_{*}\right.$, $\left.\mathrm{D}_{\mathrm{P}}(\mathrm{q})\right)$ as $\mathrm{E}^{*}\left(\mathrm{k}_{*}, \mathrm{D}_{\mathrm{P}}(\mathrm{q})\right)=\mathrm{E}\left(\mathrm{k}_{*}, \mathrm{D}_{\mathrm{P}}(\mathrm{q})\right)+a_{1 \mathrm{q}}(\mathrm{P}) \mathrm{E}\left(\mathrm{k}_{*}, 0_{1}\right)+---+$ $a_{\mathrm{Lq}}(\mathrm{P}) \mathrm{E}\left(\mathrm{k}_{*}, 0_{\mathrm{L}}\right)$. Here, each $\mathrm{E}\left(\mathrm{k}_{*}, 0_{\mathrm{t}}\right)$ is an encrypted form of 0 that is calculated by $S_{1},---, S_{\mathrm{J}}$ in advance. Then, $\mathrm{E}^{*}\left(\mathrm{k}_{*}, \mathrm{D}_{\mathrm{P}}(\mathrm{q})\right)$ is still decrypted to $\mathrm{D}_{\mathrm{P}}(\mathrm{q})$, but $S_{\mathrm{h}}$ cannot know the correspondence between $\mathrm{E}\left(\mathrm{k}_{\mathrm{h}^{*}}, \mathrm{D}_{\mathrm{P}}(\mathrm{q})\right)$ and $\mathrm{E}^{*}\left(\mathrm{k}_{\mathrm{h}^{*}}, \mathrm{D}_{\mathrm{P}}(\mathrm{q})\right)$, because $a_{1 \mathrm{q}}(\mathrm{P})$, ---,$a_{\mathrm{Lq}}(\mathrm{P})$ are secrets of $P$.

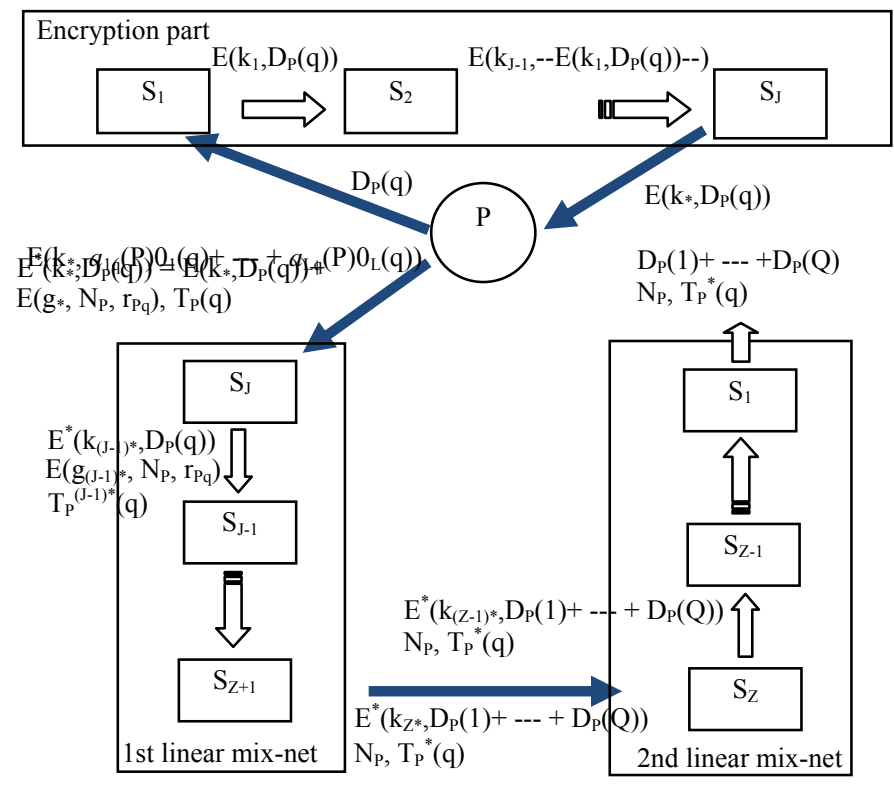

Fig. 2. Linear min-net

There are 2 problems in implementing the above scheme, the one is that $S_{\mathrm{h}}$ may calculate $\mathrm{E}\left(\mathrm{k}_{*}, \mathrm{D}_{\mathrm{P}}(\mathrm{q})\right)$ dishonestly, and the other is that $P$ may construct $\mathrm{E}^{*}\left(\mathrm{k}_{*}, \mathrm{D}_{\mathrm{P}}(\mathrm{q})\right)$ dishonestly, e.g. $P$ must pay more than it is responsible as machine maintenance fees in the former case, and in the latter case $S$ cannot collect exact fees from $P$. Fortunately $\mathrm{E}(\mathrm{k} *, x)$ and $\mathrm{E}^{*}(\mathrm{k} *, x)$ can be made verifiable because they are additive.

About the former threat conceptually, $S$ prepares test bit strings test(1), test(2), ---, test $(\mathrm{L} *)$, and $S_{1},---, S_{\mathrm{J}}$ encrypt them repeatedly to $\mathrm{E}\left(\mathrm{k}_{*}\right.$, test $\left.(1)\right), \mathrm{E}\left(\mathrm{k}_{*}\right.$, test $\left.(2)\right)$, ---, $\mathrm{E}\left(\mathrm{k}_{*}\right.$, test $\left.\left(\mathrm{L}_{*}\right)\right)$ in advance. After that at a time when $S_{1},---, S_{\mathrm{J}}$ calculate $\mathrm{E}\left(\mathrm{k}_{*}\right.$, $\left.\mathrm{D}_{\mathrm{P}}(\mathrm{q})\right), P$ asks them to decrypt $\mathrm{E}\left(\mathrm{k}_{*}\right.$, test $)=\mathrm{E}\left(\mathrm{k}_{*}, \mathrm{D}_{\mathrm{P}}(\mathrm{q})\right)+$ $v_{1 \mathrm{q}}(P) \mathrm{E}(\mathrm{k} *$, test $(1))+---+v_{\mathrm{L}^{*}}(P) \mathrm{E}(\mathrm{k} *$, test $(\mathrm{L} *))$ while generating its secret numbers $v_{1 \mathrm{q}}(P), v_{2 \mathrm{q}}(P)$---, $v_{\mathrm{L}^{*} \mathrm{q}}(P)$. Then, $P$ can convince itself that $S_{1},---, S_{\mathrm{J}}$ are honest if the decryption result coincides with test $=\mathrm{D}_{\mathrm{P}}(\mathrm{q})+v_{1 \mathrm{q}}(P)$ test $(1)+---+$ $v_{\mathrm{L}^{*} \mathrm{q}}(P)$ test $\left(\mathrm{L}_{*}\right)$. Namely, if $\mathrm{E}\left(\mathrm{k}_{*}, \mathrm{D}_{\mathrm{P}}(\mathrm{q})\right)$ is correct, $S_{1},---, S_{\mathrm{J}}$ that know their secret keys can easily decrypt $\mathrm{E}(\mathrm{k} *$, test $)$ to test, but if $\mathrm{E}\left(\mathrm{k} *, \mathrm{D}_{\mathrm{P}}(\mathrm{q})\right)$ is incorrect, they cannot calculate test because they do not know $v_{1 \mathrm{q}}(P)$, ---, $v_{\mathrm{L} * \mathrm{q}}(P)$. Actually, $\mathrm{E}(\mathrm{k} *$, $\left.\mathrm{D}_{\mathrm{P}}(\mathrm{q})\right)$ is a G-dimensional vector, and each $S_{\mathrm{h}}$ can obtain Gequations to calculate $v_{1 \mathrm{q}}(P),---, v_{\mathrm{L} * \mathrm{q}}(P)$. Therefore, L* must be greater than $\mathrm{G}$, and this means $P$ can obtain many plain 
texts and their encrypted forms pairs if $L_{*}$ is large. Although the scheme is still strong enough, to make the scheme more secure L* must remain as small as possible. A simple extension makes $\mathrm{L} *$ small enough [8].

The latter threat also can be removed, i.e. $S$ can detect dishonest construction of $\mathrm{E}^{*}\left(\mathrm{k}_{*}, \mathrm{D}_{\mathrm{P}}(\mathrm{q})\right)$ and can identify the corresponding dishonest entity $P$ in the following way. Firstly, $S$ calculates $\operatorname{Sum}(\mathrm{q})=u_{1 \mathrm{q}} \mathrm{D}_{1}(\mathrm{q})+u_{2 \mathrm{q}} \mathrm{D}_{2}(\mathrm{q})+---+u_{\underline{L} q} \mathrm{D}_{\underline{L}}(\mathrm{q})(\underline{\mathrm{L}}$ is the number of members) and $\mathrm{E}^{*}(\mathrm{k} *, \underline{\operatorname{Sum}}(\mathrm{q}))=u_{1 \mathrm{q}} \mathrm{E}^{*}(\mathrm{k} *$, $\left.\mathrm{D}_{1}(\mathrm{q})\right)+---+u_{\underline{\mathrm{L} q}} \mathrm{E}^{*}\left(\mathrm{k}_{*}, \mathrm{D}_{\underline{\mathrm{L}}}(\mathrm{q})\right)$ while generating secret numbers $u_{1 \mathrm{q}},---, u_{\underline{\mathrm{Lq}}}$, and $S_{\mathrm{J}},---, S_{1} \operatorname{decrypt} \mathrm{E}^{*}(\mathrm{k} *, \underline{\operatorname{Sum}}(\mathrm{q}))$. Then, $S$ convinces itself that each $\mathrm{E}^{*}\left(\mathrm{k}_{*}, \mathrm{D}_{\mathrm{P}}(\mathrm{q})\right)$ is correct when $\mathrm{E}^{*}(\mathrm{k} *$ Sum $(\mathrm{q}))$ is decrypted to $\operatorname{Sum}(\mathrm{q})$. Namely, if $\mathrm{E}^{*}\left(\mathrm{k}_{*}\right.$, $\left.\mathrm{D}_{\mathrm{P}}(\mathrm{q})\right)$ is an encrypted form of $\mathrm{X}, \mathrm{E}^{*}(\mathrm{k} * \underline{\operatorname{Sum}}(\mathrm{q}))$ is decrypted to $\operatorname{Sum}(\mathrm{q})+u_{\mathrm{P}}\left(\mathrm{X}-\mathrm{D}_{\mathrm{P}}(\mathrm{q})\right)$. On the other hand, each $S_{\mathrm{h}}$ can know only a partially decrypted form $\mathrm{E}^{*}\left(\mathrm{k}_{\mathrm{h}^{*}}, \underline{\operatorname{Sum}}(\mathrm{q})\right)$, it cannot know $\mathrm{E}^{*}\left(\mathrm{k}_{\mathrm{h}} * \mathrm{D}_{\mathrm{P}}(\mathrm{q})\right)$, i.e. $S_{\mathrm{h}}$ cannot identify the correspondence between $\mathrm{E}^{*}\left(\mathrm{k}_{*}, \mathrm{D}_{\mathrm{P}}(\mathrm{q})\right)$ and $\mathrm{E}^{*}\left(\mathrm{k}_{\mathrm{h}^{*}}, \mathrm{D}_{\mathrm{P}}(\mathrm{q})\right)$. Because $u_{1 \mathrm{q}},---, u_{\underline{\mathrm{Lq}}}$ are secret of $S$, even conspiring entities $P_{1}$ and $P_{2}$ cannot encrypt their data dishonestly either, i.e. although $P_{1}$ can consistently calculate $E^{*}\left(\mathrm{k}_{*}, \mathrm{X}\right)$ instead of $\mathrm{E}^{*}\left(\mathrm{k}_{*}, \mathrm{D}_{\mathrm{P} 1}(\mathrm{q})\right)$ as the encrypted form of $\mathrm{D}_{\mathrm{P}}(\mathrm{q})$ if $P_{2}$ calculates $\mathrm{E}^{*}\left(\mathrm{k}_{*}, \mathrm{D}_{\mathrm{P} 2}(\mathrm{q})\right)-\mathrm{E}^{*}\left(\mathrm{k}_{*}\right.$, $\left.\left(u_{\mathrm{P} 1} / u_{\mathrm{P} 2}\right)\left(\mathrm{X}-\mathrm{D}_{\mathrm{P} 1}(\mathrm{q})\right)\right)$ instead of $\mathrm{E}^{*}\left(\mathrm{k} *, \mathrm{D}_{\mathrm{P} 2}(\mathrm{q})\right)$, either $P_{1}$ or $P_{2}$ that does not know $u_{(\mathrm{P} 1) \mathrm{q}}$ or $u_{(\mathrm{P} 2) \mathrm{q}}$ cannot calculate $\left.\left(u_{(\mathrm{P} 1) \mathrm{q}} / u_{(\mathrm{P} 2) \mathrm{q}}\right) \mathrm{E}^{*}\left(\mathrm{k}_{*}, \mathrm{X}-\mathrm{D}_{\mathrm{P} 1}(\mathrm{q})\right)\right)$.

Once dishonesties are detected, for each triple $\left\{D_{P}(q)\right.$, $\left.\mathrm{E}\left(\mathrm{k}_{*}, \mathrm{D}_{\mathrm{P}}(\mathrm{q})\right), \mathrm{T}_{\mathrm{P}}(\mathrm{q})\right\}, S_{\mathrm{J}},---, S_{1}$ decrypt $\mathrm{E}\left(\mathrm{k}_{*}, \mathrm{D}_{\mathrm{P}}(\mathrm{q})\right)$, and if $\mathrm{E}\left(\mathrm{k} *, \mathrm{D}_{\mathrm{P}}(\mathrm{q})\right)$ is not decrypted to $\mathrm{D}_{\mathrm{P}}(\mathrm{q})$, identify $P$ as dishonest entity while exploiting anonymous credential $T_{P}(q)$ as will be discussed later. However after dishonest entities are identified, honest members must ask $S_{1},---, S_{\mathrm{J}}$ to encrypt their data again to conceal linkages between their owning data.

\section{ANONYMOUS TAG BASED CREDENTIALS}

\section{A. Anonymous Tags}

An anonymous tag is a tag and associate tag parts pair $\{\mathrm{T}$, $\mathrm{T}^{\mathrm{R}}$, , i.e. tag owner $P$ places $\mathrm{T}$ in the tag part and transforms it to $\mathrm{T}^{\mathrm{R}}$ mod $\mathrm{B}$ by its secret integer $\mathrm{R}$ to put the result in the associate tag part [7], where as shown in Sec. III, B is an appropriate integer common to all entities and large enough. Also, $P$ uses tag $\left\{\mathrm{T}, \mathrm{T}^{\mathrm{R}}\right\}$ while transforming it to $\left\{\mathrm{T}^{\mathrm{W}}{ }_{\bmod \mathrm{B}}\right.$, $\left.\mathrm{T}^{\mathrm{RW}}{ }_{\text {mod B }}\right\}$ by its secret integer $\mathrm{W}$, and entity $S_{\mathrm{h}}$ transforms tags it receives by its secret integer $\mathrm{k}_{\mathrm{h}}$. Therefore, $\left\{\mathrm{T}, \mathrm{T}^{\mathrm{R}}\right\}$ changes its form as $\left\{\mathrm{T}^{\mathrm{W}(\mathrm{k} 1)}, \mathrm{T}^{\mathrm{RW}(\mathrm{k} 1)}\right\}, \quad\left\{\mathrm{T}^{\mathrm{W}(\mathrm{k} 1)(\mathrm{k} 2)}, \mathrm{T}^{\mathrm{RW}(\mathrm{k} 1)(\mathrm{k} 2)}\right\}$ and $\left\{\mathrm{T}^{\mathrm{W}(\mathrm{k} 1)(\mathrm{k} 2)(\mathrm{k} 3)}, \mathrm{T}^{\mathrm{RW}(\mathrm{k} 1)(\mathrm{k} 2)(\mathrm{k} 3)}\right\}$ in this order when it is transformed by $P$ and 3 entities $S_{1}, S_{2}, S_{3}$. Then, anonymous tags satisfy the following requirements, i.e.

1) anyone except $P$ cannot identify $P$ from its tag,

2) anyone except $P$ cannot know that different forms of tag $\left\{\mathrm{T}, \mathrm{T}^{\mathrm{R}}\right\}$ are owned by a same entity, unless all relevant entities conspire with each other, and

3) $P$ can identify its tag without knowing secrets of others.

About requirement 3), $P$ can identify its tag by transforming the tag part by its secret $\mathrm{R}$, e.g. $P$ can identify $\left\{\mathrm{T}^{\mathrm{W}(\mathrm{k} 1)(\mathrm{k} 2)}, \mathrm{T}^{\mathrm{RW}(\mathrm{k} 1)(\mathrm{k} 2)}\right\}$ as its tag by calculating the associate tag part value from tag part value $\mathrm{T}^{\mathrm{W}(\mathrm{k} 1)(\mathrm{k} 2)}$ as $\left(\mathrm{T}^{\mathrm{W}(\mathrm{k} 1)(\mathrm{k} 2)}\right)^{\mathrm{R}}$. Here, it is apparent that $P$ does not need to know secret integers $\mathrm{k}_{1}, \mathrm{k}_{2}$, -- to identify its tags.

\section{B. Anonymous Credentials Based on Anonymous Tags}

Let $\mathrm{T}_{\mathrm{P}}, k$ and $c$ be integers defined by authority $S$, and $\mathrm{R}$ and $w$ be secret integers defined by member $P$. Then, provided that $d_{1}$ and $d_{2}$ are 2 secret signing keys of $S$ and $S\left(d_{1 \|} d_{2}, x\right)$ is RSA signature pair $\left\{\mathrm{S}\left(\mathrm{d}_{1}, x\right)=x^{\mathrm{d} 1} \bmod \mathrm{B}, \mathrm{S}\left(\mathrm{d}_{2}, x\right)=x^{\mathrm{d} 2}{ }_{\bmod \mathrm{B}}\right\}$, signature pair $S\left(d_{1 \|} d_{2}, T_{P}{ }^{R+1} K_{w} C_{w}{ }^{R}\right.$ mod $\left.B\right)$ is an anonymous tag based anonymous credential generated by $S$ and given to $P$ (it must be noted that RSA signing function is multiplicative, i.e. relation $\mathrm{S}(\mathrm{d}, x) \mathrm{S}(\mathrm{d}, y)=\mathrm{S}(\mathrm{d}, x y)$ holds $)$. Here, $\mathrm{T}_{\mathrm{P}}, k$ and $c$ are publicly known integers, and different from $k$ and $c$ that are common to all credentials $T_{P}$ and $R$ are unique to credential $\mathrm{S}\left(\mathrm{d}_{1 \|} \mathrm{d}_{2}, \mathrm{~T}_{\mathrm{P}}{ }^{\mathrm{R}+1} \mathrm{~K}_{w} \mathrm{C}_{w}{ }^{\mathrm{R}}\right)$. Regarding $\mathrm{K}_{w}$ and $\mathrm{C}_{w}, P$ calculates them as $\mathrm{K}_{w}=k^{w}{ }_{\text {mod B }}$ and $\mathrm{C}_{w}=c^{w}{ }_{\text {mod B }}$, respectively based on $k$ and $c$. Also uniqueness of $P$ 's secret integer $\mathrm{R}$ can be maintained in the same way as in Sec. III.

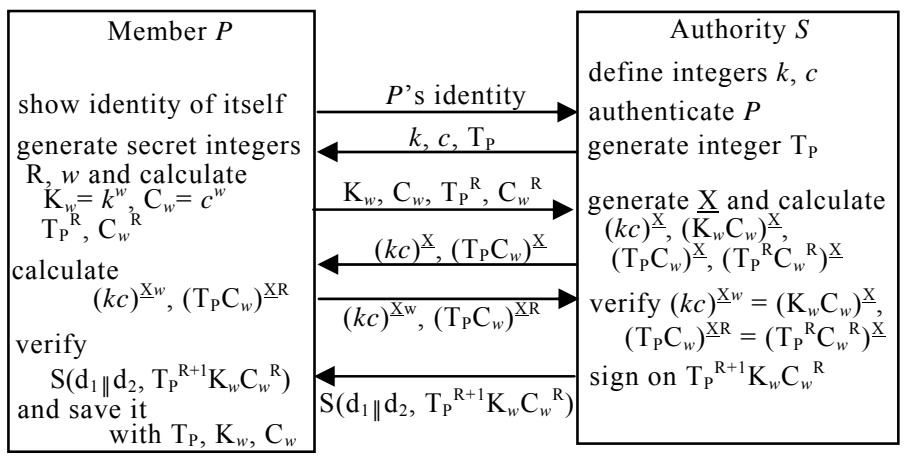

Fig. 3. Issuing anonymous credentials

Fig. 3 shows the procedure in which $S$ issues $S\left(d_{1 \|} d_{2}\right.$, $\mathrm{T}_{\mathrm{P}}{ }^{\mathrm{R}+1} \mathrm{~K}_{\mathrm{w}} \mathrm{C}_{\mathrm{w}}{ }^{\mathrm{R}}$ ) to $P$. Firstly, after verifying authenticity of $P$ based on $P$ 's identity, $S$ defines integer $\mathrm{T}_{\mathrm{P}}$, and $P$ calculates $\mathrm{K}_{w}$ $=k^{w}, \mathrm{C}_{w}=c^{w}$ and pair $\mathrm{T}_{\mathrm{P}}^{\mathrm{R}}$ and $\mathrm{C}_{w}^{\mathrm{R}}$ while using its secrets $w$ and $\mathrm{R}$, where $\left\{\mathrm{T}_{\mathrm{P}}, \mathrm{T}_{\mathrm{P}}{ }^{\mathrm{R}}\right\}$ constitutes an anonymous tag. Then $S$ generates credential $S\left(d_{1} \| d_{2}, T_{P}{ }^{R+1} K_{w} C_{w}{ }^{R}\right)$ to give it to $P$. Here, it must be noted that although $\mathrm{T}_{\mathrm{P}}{ }^{\mathrm{R}}, k^{w}, c^{w}$ and $\mathrm{C}_{w}{ }^{\mathrm{R}}$ are disclosed, to know $w$ and $\mathrm{R}$ is practically impossible for $S$ as mentioned before. Nevertheless, $S$ can confirm that $P$ had calculated $\mathrm{K}_{w}$ and $C_{w}$ as $k$ and $c$ to the power of same $w$ through the scheme of Diffie and Hellman [1], i.e. $S$ generates secret integer $\underline{X}$ to calculate $(k c)^{\underline{\mathrm{X}}}$ and $\left(\mathrm{K}_{w} \mathrm{C}_{w}\right)^{\underline{\mathrm{X}}}$, and asks $P$ to calculate $(k c)^{\underline{\mathrm{X}} w}$ while showing $(k c)^{\underline{X}}$. If $P$ does not know $w$ that satisfies relation $\mathrm{K}_{w}=k^{w}$ and $\mathrm{C}_{w}=c^{w}$, it cannot calculate $(k c)^{\underline{\mathrm{X}} w}=$ $\left(\mathrm{K}_{w} \mathrm{C}_{w}\right)^{\underline{X}}$ from $(k c)^{\underline{X}}$ without knowing $S$ 's secret $\underline{X}$ (actually, it is easy to find $\alpha$ and $\beta$ that satisfy $\alpha \beta=(k c)^{w}$ by defining $\alpha$ arbitrarily and calculating $\beta=(k c)^{w} / \alpha$, and $P$ can report $\alpha$ and $\beta$ to $S$ instead of $k^{w}$ and $c^{w}$ while calculating $(\alpha \beta)^{\underline{X}}$ that is equal to $(k c)^{\underline{X} w}$. However in this case, $P$ that does not know $\gamma$ or $\delta$ that satisfies $\alpha=k^{\gamma}$ or $\beta=c^{\delta}$ cannot calculate $\alpha^{\underline{Y}}=k^{\gamma \underline{Y}}$ or $\beta^{\underline{Y}}=$ $c^{\delta \underline{Y}}$ when $S$ generates secret integer $\underline{Y}$ and asks $P$ to calculate them from $k^{\underline{Y}}$ or $c^{\underline{Y}}$ ). In the same way, $S$ can confirm that $T_{P}{ }^{R}$ and $\mathrm{C}_{w}{ }^{\mathrm{R}}$ are equal to $\mathrm{T}_{P}$ and $\mathrm{C}_{w}$ to the power of same unknown integer $\mathrm{R}$. 
After having obtained $\mathrm{S}\left(\mathrm{d}_{1 \|} \mathrm{d}_{2}, \mathrm{~T}_{\mathrm{P}}{ }^{\mathrm{R}+1} \mathrm{~K}_{w} \mathrm{C}_{w}{ }^{\mathrm{R}}\right)$, by generating secret integer $\mathrm{W}$, calculating $\mathrm{S}\left(\mathrm{d}_{1 \|} \mathrm{d}_{2}, \mathrm{~T}_{\mathrm{P}}{ }^{\mathrm{R}+1} \mathrm{~K}_{w} \mathrm{C}_{w}{ }^{\mathrm{R}}\right)^{\mathrm{W}}=\mathrm{S}\left(\mathrm{d}_{1 \|} \mathrm{d}_{2}\right.$, $\left.\left(\mathrm{T}_{\mathrm{P}}{ }^{\mathrm{R}+1} \mathrm{~K}_{w} \mathrm{C}_{w}{ }^{\mathrm{R}}\right)^{\mathrm{W}}\right)$ and showing it together with $\mathrm{T}_{\mathrm{P}}{ }^{\mathrm{W}}, \mathrm{K}_{w}{ }^{\mathrm{W}}, \mathrm{C}_{w}{ }^{\mathrm{W}}$ and $\mathrm{C}_{w}{ }^{\mathrm{RW}}, P$ can convince any entity $V$ that it is an eligible entity ensured by $S$ without disclosing its identity as shown in Fig. 4. Namely, $V$ verifies that $S\left(d_{1 \|} d_{2}, T_{P}{ }^{R+1} K_{w} C_{w}{ }^{R}\right)^{W}$ is the legitimate signature pair on $\left(\mathrm{T}_{\mathrm{P}}{ }^{\mathrm{R}+1} \mathrm{~K}_{w} \mathrm{C}_{w}{ }^{\mathrm{R}}\right)^{\mathrm{W}}$ by using public verification key pair $\mathrm{d}_{1^{*}}$ and $\mathrm{d}_{2^{*}}$ (pair $\mathrm{S}\left(\mathrm{d}_{1 \|} \mathrm{d}_{2}, x\right)$ is consistent when not only $S\left(d_{1}, x\right)$ and $S\left(d_{2}, x\right)$ are consistent signatures but also they are decrypted into same $x$ ), decomposes it into $\mathrm{T}_{\mathrm{P}}{ }^{\mathrm{W}}$, $\mathrm{T}_{\mathrm{P}}{ }^{\mathrm{RW}}, \mathrm{K}_{w}{ }^{\mathrm{W}}$ and $\mathrm{C}_{w}{ }^{\mathrm{RW}}$ based on the information given by $P$, and confirms that $P$ had calculated $\mathrm{K}_{w}{ }^{\mathrm{W}}=k^{w \mathrm{~W}}$ and $\mathrm{C}_{w}{ }^{\mathrm{W}}=c^{w \mathrm{~W}}$ based on integers $k, c$ and same unknown secret integer $w \mathrm{~W}$ in the same way as $S$ had verified pair $\left\{\mathrm{K}_{w}, \mathrm{C}_{w}\right\}$ in Fig. 3 .

Then, because no one other than the legitimate holder of $\mathrm{S}\left(\mathrm{d}_{1} \| \mathrm{d}_{2}, \mathrm{~T}_{\mathrm{P}}{ }^{\mathrm{R}+1} \mathrm{~K}_{w} \mathrm{C}_{w}{ }^{\mathrm{R}}\right)$ knows $\mathrm{R}, V$ can determine $P$ is eligible when $P$ knows R. Where $P$ can prove that it knows $\mathrm{R}$ without disclosing $\mathrm{R}$ itself also through the scheme of Diffie and Hellman [1], i.e. $V$ calculates $\left(\mathrm{T}_{\mathrm{P}}{ }^{\mathrm{W}} \mathrm{C}_{w}{ }^{\mathrm{W}}\right)^{\mathrm{X}}$ and $\left(\mathrm{T}_{\mathrm{P}}{ }^{\mathrm{RW}} \mathrm{C}_{w}{ }^{\mathrm{RW}}\right)^{\mathrm{X}}$ while generating its secret integer $\mathrm{X}$, and $P$ that receives $\left(\mathrm{T}_{\mathrm{P}}{ }^{\mathrm{W}} \mathrm{C}_{w}{ }^{\mathrm{W}}\right)^{\mathrm{X}}$ calculates $D=\left(\left(\mathrm{T}_{\mathrm{P}}{ }^{\mathrm{W}} \mathrm{C}_{w}{ }^{\mathrm{W}}\right)^{\mathrm{X}}\right)^{\mathrm{R}}$ by using its secret $\mathrm{R}$, then finally, $V$ determines that $P$ knows $\mathrm{R}$ when relation $D=$ $\left(\mathrm{T}_{\mathrm{P}}{ }^{\mathrm{RW}} \mathrm{C}_{w}{ }^{\mathrm{RW}}\right)^{\mathrm{X}}$ holds. Namely, although it is easy to calculate $\left(\mathrm{T}_{\mathrm{P}}{ }^{\mathrm{RW}} \mathrm{C}_{w}{ }^{\mathrm{RW}}\right)^{\mathrm{X}}$ from $\left(\mathrm{T}_{\mathrm{P}}{ }^{\mathrm{W}} \mathrm{C}_{w}{ }^{\mathrm{W}}\right)^{\mathrm{X}}$ for an entity that knows $\mathrm{R}$, for entities that do not know $R$ calculating $\left(\mathrm{T}_{\mathrm{P}}{ }^{\mathrm{RW}} \mathrm{C}_{w}{ }^{\mathrm{RW}}\right)^{\mathrm{X}}$ is practically impossible.

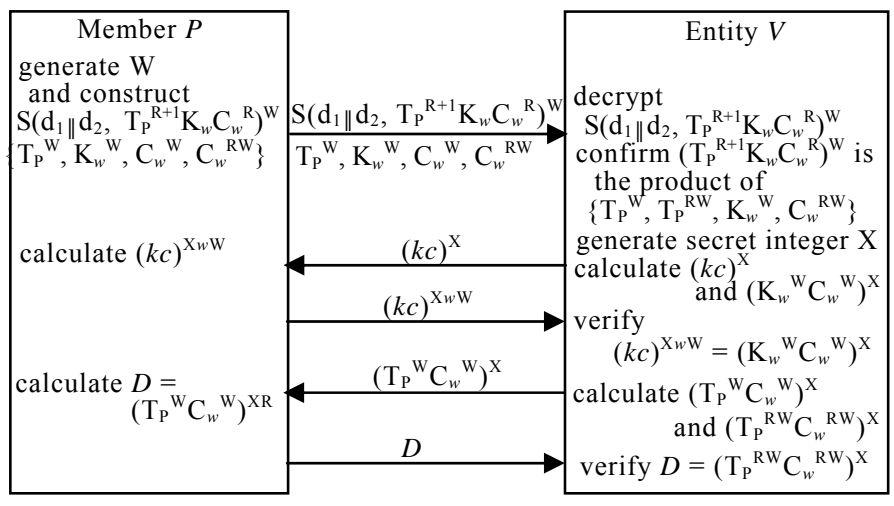

Fig. 4. Verifying anonymous credentials

Now, the above procedures are characterized by the following 4 properties, i.e.

1) $P$ can obtain credential $\mathrm{S}\left(\mathrm{d}_{1} \| \mathrm{d}_{2}, \mathrm{~T}_{\mathrm{P}}{ }^{\mathrm{R}+1} \mathrm{~K}_{w} \mathrm{C}_{w}{ }^{\mathrm{R}}\right)$ from $S$ only through legitimate ways and only when it is eligible,

2) only $P$ that knows integer $\mathrm{R}$ can prove the ownership of $\mathrm{S}\left(\mathrm{d}_{1 \|} \mathrm{d}_{2}, \mathrm{~T}_{\mathrm{P}}^{\mathrm{R}+1} \mathrm{~K}_{w} \mathrm{C}_{w}{ }^{\mathrm{R}}\right)$

3) no one except $P$ can identify $P$ from its credential $S\left(d_{1} \| d_{2}\right.$, $\left.\mathrm{T}_{\mathrm{P}}{ }^{\mathrm{R}+1} \mathrm{~K}_{w} \mathrm{C}_{w}{ }^{\mathrm{R}}\right)^{\mathrm{W}}$. Provided that $\mathrm{W}_{1},---, \mathrm{W}_{\mathrm{N}}$ are different integers secrets of $P$, no one other than $P$ can know that $\mathrm{S}\left(\mathrm{d}_{1 \|} \mathrm{d}_{2}, \mathrm{~T}_{\mathrm{P}}{ }^{\mathrm{R}+1} \mathrm{~K}_{w} \mathrm{C}_{w}{ }^{\mathrm{R}}\right)^{\mathrm{W} 1},---, \mathrm{S}\left(\mathrm{d}_{1 \|} \mathrm{d}_{2}, \mathrm{~T}_{\mathrm{P}}{ }^{\mathrm{R}+1} \mathrm{~K}_{w} \mathrm{C}_{w}{ }^{\mathrm{R}}\right)^{\mathrm{WN}}$ are different forms of same credential $S\left(d_{1} \| d_{2}, T_{P}{ }^{R+1} K_{w} C_{w}{ }^{R}\right)$ either, and

4) $P$ that shows credential $\mathrm{S}\left(\mathrm{d}_{1} \| \mathrm{d}_{2}, \mathrm{~T}_{\mathrm{P}}{ }^{\mathrm{R}+1} \mathrm{~K}_{w} \mathrm{C}_{w}{ }^{\mathrm{R}}\right)^{\mathrm{W}}$ can prove its ownership only when it calculates $D=\left(\mathrm{T}_{\mathrm{P}}{ }^{\mathrm{W}} \mathrm{C}_{w}{ }^{\mathrm{W}}\right)^{\mathrm{XR}}$ as $\left(\mathrm{T}_{\mathrm{P}}{ }^{\mathrm{W}} \mathrm{C}_{w}{ }^{\mathrm{W}}\right)^{\mathrm{X}}$ to the power of exactly $\mathrm{R}$.
In addition, any entity can verify the validity of $\mathrm{S}\left(\mathrm{d}_{1} \| \mathrm{d}_{2}\right.$, $T_{P}{ }^{R+1} K_{w} C_{w}{ }^{R}$ ) because verification keys $d_{1 *}$ and $d_{2 *}$ are publicly known and $\left(\mathrm{T}_{\mathrm{P}}{ }^{\mathrm{R}+1} \mathrm{~K}_{w} \mathrm{C}_{w}{ }^{\mathrm{R}}\right)^{\mathrm{W}}$ is decomposed into $\mathrm{T}_{\mathrm{P}}{ }^{\mathrm{RW}}, \mathrm{T}_{\mathrm{P}}{ }^{\mathrm{W}}, \mathrm{K}_{w}{ }^{\mathrm{W}}$ and $\mathrm{C}_{w}{ }^{\mathrm{RW}}$ by $P$ itself. Here, property 4$)$ in the above are ensured because $V$ examines whether $\mathrm{K}_{w}{ }^{w}$ and $\mathrm{C}_{w}{ }^{w}$ are calculated as publicly known integers $k$ and $c$ to the power of same unknown integer $w \mathrm{~W}$, and $\mathrm{T}_{\mathrm{P}}{ }^{\mathrm{RW}}$ and $\mathrm{C}_{w}{ }^{\mathrm{RW}}$ are equal to $\mathrm{T}_{\mathrm{P}}{ }^{\mathrm{W}}$ and $\mathrm{C}_{w}{ }^{\mathrm{W}}$ to the power of same unknown integer $\mathrm{R}$, in the same way as $S$ in Fig. 3 examines relation $\mathrm{K}_{w}=k^{w}$ and $\mathrm{C}_{w}=c^{w}$. Also a signature pair disables entities to forge a credential while generating $\alpha, \beta$ and $\delta$ arbitrarily and calculating $\alpha^{\beta} k^{\delta} c^{\beta \delta}$ to transform it by a publicly known verification key.

About anonymity of credentials, when 2 entities $P$ and $P_{*}$ use $\mathrm{S}\left(\mathrm{d}_{1 \|} \mathrm{d}_{2}, \mathrm{~T}_{\mathrm{P}}^{\mathrm{R}+1} \mathrm{~K}_{w} \mathrm{C}_{w}{ }^{\mathrm{R}}\right)^{\mathrm{W}}$ and $\mathrm{S}\left(\mathrm{d}_{1 \|} \mathrm{d}_{2}, \mathrm{~T}_{\mathrm{P}^{*}}{ }^{\mathrm{R}^{*+1}} \mathrm{~K}_{w^{*}} \mathrm{C}_{w^{*}} \mathrm{R}^{*}\right)^{\mathrm{W}^{*}}$ while defining integer pairs $\{w, W\}$ and $\left\{W_{*}, W_{*}\right\}$ in the way relation $w \mathrm{~W}=w * \mathrm{~W} *$ holds by chance, $S$ (it is assumed that authority $S$ itself verifies credentials) can detect this fact by duplicated appearances of $\mathrm{K}_{w}{ }^{\mathrm{W}}\left(=k^{w \mathrm{~W}}\right)$ and if $S$ is conspiring with $P_{*}$, it can know $w \mathrm{~W}\left(=w_{*} \mathrm{~W}_{*}\right)$ by asking it to $P_{*}$. But $S$ cannot identify $P$ from $w \mathrm{~W}$, i.e. $S$ that knows only $w \mathrm{~W}$ cannot extract $W$ and calculate $T_{j}{ }^{W}$ for each $T_{j}$ it had assigned to member $P_{\mathrm{j}}$ to compare the result with $\mathrm{T}_{\mathrm{P}}{ }^{\mathrm{W}}$ that $P$ shows together with $\mathrm{S}\left(\mathrm{d}_{1 \|} \mathrm{d}_{2}, \mathrm{~T}_{\mathrm{P}}^{\mathrm{R}+1} \mathrm{~K}_{w} \mathrm{C}_{w}{ }^{\mathrm{R}}\right)^{\mathrm{W}}$.

\section{Anonymous Tag Based Credentials in the Proposed Scheme}

One of advantages of anonymous tag based credentials is member $P$ can show credential $\mathrm{S}\left(\mathrm{d}_{1} \| \mathrm{d}_{2}, \quad \mathrm{~T}_{\mathrm{P}}{ }^{\mathrm{R}+1} \mathrm{~K}_{\mathrm{w}} \mathrm{C}_{\mathrm{w}}{ }^{\mathrm{R}}\right)$ repeatedly while changing its forms without being detected by others that its showing forms were generated from same $\mathrm{S}\left(\mathrm{d}_{1} \| \mathrm{d}_{2}, \quad \mathrm{~T}_{\mathrm{P}}^{\mathrm{R}+1} \mathrm{~K}_{\mathrm{w}} \mathrm{C}_{\mathrm{w}}{ }^{\mathrm{R}}\right)$. Namely, provided that $P$ assigns different values to $\mathrm{W}_{1},---, \mathrm{W}_{\mathrm{N}}$, no one except $P$ can know that $\mathrm{S}\left(\mathrm{d}_{1 \|} \mathrm{d}_{2}, \quad \mathrm{~T}_{\mathrm{P}}^{\mathrm{R}+1} \mathrm{~K}_{\mathrm{w}} \mathrm{C}_{\mathrm{w}}{ }^{\mathrm{R}}\right)^{\mathrm{W} 1}, \quad---, \quad \mathrm{S}\left(\mathrm{d}_{1 \|} \mathrm{d}_{2}, \quad \mathrm{~T}_{\mathrm{P}}^{\mathrm{R}+1} \mathrm{~K}_{\mathrm{w}} \mathrm{C}_{\mathrm{w}}{ }^{\mathrm{R}}\right)^{\mathrm{WN}}$ are shown by $P$. While exploiting this property, credentials $T_{P}(0)$, $\mathrm{T}_{\mathrm{P}}(1)$, ---, $\mathrm{T}_{\mathrm{P}}(\mathrm{Q})$ in Sec. II can be implemented as $\mathrm{S}\left(\mathrm{d}_{1} \| \mathrm{d}_{2}\right.$, $\left.\mathrm{T}_{\mathrm{P}}^{\mathrm{R}+1} \mathrm{~K}_{\mathrm{w}} \mathrm{C}_{\mathrm{w}}{ }^{\mathrm{R}}\right), \quad \mathrm{S}\left(\mathrm{d}_{1} \| \mathrm{d}_{2}, \quad \mathrm{~T}_{\mathrm{P}}^{\mathrm{R}+1} \mathrm{~K}_{\mathrm{w}} \mathrm{C}_{\mathrm{w}}{ }^{\mathrm{R}}\right)^{\mathrm{W} 1}, \quad---, \quad \mathrm{S}\left(\mathrm{d}_{1} \| \mathrm{d}_{2}\right.$, $\left.\mathrm{T}_{\mathrm{P}}^{\mathrm{R}+1} \mathrm{~K}_{\mathrm{w}} \mathrm{C}_{\mathrm{w}}^{\mathrm{R}}\right)^{\mathrm{WQ}}$, respectively.

As another feature relates to data collection systems, anonymous tag based credentials enable authority $S$ to identify dishonest members of course without knowing privacy of honest entities. To identify dishonest members, when $P$ puts data $D_{P}(q)$ in the distributed data storage while showing credential $\mathrm{S}\left(\mathrm{d}_{1 \|} \mathrm{d}_{2}, \mathrm{~T}_{\mathrm{P}}{ }^{\mathrm{R}+1} \mathrm{~K}_{\mathrm{w}} \mathrm{C}_{\mathrm{w}}{ }^{\mathrm{R}}\right)^{\mathrm{Wq}}, S$ memorizes pair $\left\{U_{\mathrm{P}}(\mathrm{q})\right.$, $\left.U_{\mathrm{P}}(\mathrm{q})^{\mathrm{R}}\right\}$ as a data registration record. Here, $S$ defines $U_{\mathrm{P}}(\mathrm{q})$ as an integer unique to data $D_{P}(q) . U_{P}(q)^{R}$ is the used seal of tag $\left\{\mathrm{T}_{\mathrm{P}}, \mathrm{T}_{\mathrm{P}}{ }^{\mathrm{R}}\right\}$ and $S$ asks $P$ to calculate it based on credential $\mathrm{S}\left(\mathrm{d}_{1} \| \mathrm{d}_{2}, \mathrm{~T}_{\mathrm{P}}{ }^{\mathrm{R}+1} \mathrm{~K}_{\mathrm{w}} \mathrm{C}_{\mathrm{w}}{ }^{\mathrm{R}}\right)^{\mathrm{Wq}}$. Under these settings, if $S$ detects that no entity completes actions about the sum accompanied by $\left\{U_{\mathrm{P}}(1), U_{\mathrm{P}}(1)^{\mathrm{R}}\right\}$, each member $P_{*}$ is requested to calculate $U_{\mathrm{P}}(1)^{\mathrm{R}^{*}}$ from its credential $\mathrm{S}\left(\mathrm{d}_{1 \|} \mathrm{d}_{2}, \mathrm{~T}_{\mathrm{P}^{*}}{ }^{\mathrm{R}^{*}+1} \mathrm{~K}_{\mathrm{w}^{*}} \mathrm{C}_{\mathrm{w}^{*}}{ }^{\mathrm{R}^{*}}\right)$ and $U_{\mathrm{P}}(1)$ in dishonest data registration record $\left\{U_{\mathrm{P}}(1), U_{\mathrm{P}}(1)^{\mathrm{R}}\right\}$. Then, $S$ can identify $P_{*}$ as the entity responsible for the actions when $U_{\mathrm{P}}(1)^{\mathrm{R}^{*}}$ coincides with $U_{\mathrm{P}}(1)^{\mathrm{R}}$ (i.e. when $\mathrm{R}=\mathrm{R}^{*}$ ). On the other hand, $P_{*}$ can conceal the linkage between it and its data if it is honest, because it is practically impossible to know $U_{\mathrm{P}^{*}}(1)^{\mathrm{R}^{*}}$ that $P_{*}$ had left in the data registration records from $U_{\mathrm{P}}(1)^{\mathrm{R}^{*}}$.

In the above, $S$ can force $P$ to honestly calculate $U_{\mathrm{P}}(\mathrm{q})^{\mathrm{R}}$ at a time when $P$ registers $\mathrm{D}_{\mathrm{P}}(\mathrm{q})$ as below. Namely, $S$ asks $P$ to 
calculate $D=\left\{\left(\mathrm{T}_{\mathrm{P}}{ }^{\mathrm{W}} \mathrm{C}_{w}{ }^{\mathrm{W}}\right)^{\mathrm{X}}\right\}^{\mathrm{R}}, \quad A=U_{\mathrm{P}}(\mathrm{q})^{\mathrm{R}}$ and $B=$ $\left\{\left(U_{\mathrm{P}}(\mathrm{q}) \mathrm{T}_{\mathrm{P}}{ }^{\mathrm{W}} \mathrm{C}_{w}{ }^{\mathrm{W}}\right)^{\mathrm{XY}}\right\}^{\mathrm{R}}$ while showing $\left(\mathrm{T}_{\mathrm{P}}{ }^{\mathrm{W}} \mathrm{C}_{w}{ }^{\mathrm{W}}\right)^{\mathrm{X}}, U_{\mathrm{P}}(\mathrm{q})$ and $\left(U_{\mathrm{P}}(\mathrm{q}) \mathrm{T}_{\mathrm{P}}{ }^{\mathrm{W}} \mathrm{C}_{w}{ }^{\mathrm{W}}\right)^{\mathrm{XY}}$, where $\mathrm{X}$ and $\mathrm{Y}$ are $S$ 's secret integers. After that, $S$ examines whether relations $D=\left(\mathrm{T}_{\mathrm{P}}{ }^{\mathrm{RW}} \mathrm{C}_{w}{ }^{\mathrm{RW}}\right){ }^{\mathrm{X}}$ and $B=$ $\left(A^{\mathrm{XY}}\right) D^{\mathrm{Y}}$ hold or not. Then, if $P$ calculates $A$ dishonestly as $U_{\mathrm{P}}(\mathrm{q})^{\mathrm{Q}}(\mathrm{Q} \neq \mathrm{R})$, because $D$ must be equal to $\left\{\left(\mathrm{T}_{\mathrm{P}}{ }^{\mathrm{W}} \mathrm{C}_{w}{ }^{\mathrm{W}}\right)^{\mathrm{X}}\right\}^{\mathrm{R}}$ (according to property-4 in the previous subsection, if $P$ calculates $D$ differently it cannot show the ownership of $\left\{\mathrm{T}_{\mathrm{P}}\right.$, $\left.\left.\mathrm{T}_{\mathrm{P}}{ }^{\mathrm{R}}\right\}\right), P$ must calculate $B$ so that it coincides with $\left(A^{\mathrm{XY}}\right) D^{\mathrm{Y}}=$ $\left.\left(U_{\mathrm{P}}(\mathrm{q})^{\mathrm{QXY}}\right)\left(\mathrm{T}_{\mathrm{P}}{ }^{\mathrm{RW}} \mathrm{C}_{w}{ }^{\mathrm{RW}}\right)^{\mathrm{XY}}\right)$, but $P$ that does not know $\mathrm{X}$ or $\mathrm{Y}$ cannot calculate $U_{\mathrm{P}}(\mathrm{q})^{\mathrm{QXY}}$. In the same way, $S$ can force $P_{*}$ to honestly calculate $U_{\mathrm{P}}(\mathrm{q})^{\mathrm{R}^{*}}$, when $S$ detects existences of dishonest members.

But actually data registration record $\left\{U_{\mathrm{P}}(1), U_{\mathrm{P}}(1)^{\mathrm{R}}\right\}$ is encrypted by $S_{\mathrm{J}},---, S_{\mathrm{z}+1}$ together with $\mathrm{T}_{\mathrm{P}}(1)=\mathrm{S}\left(\mathrm{d}_{1 \|} \mathrm{d}_{2}\right.$, $\left.\mathrm{T}_{\mathrm{P}}{ }^{\mathrm{R}+1} \mathrm{~K}_{\mathrm{W}} \mathrm{C}_{\mathrm{w}}{ }^{\mathrm{R}}\right)^{\mathrm{W} 1}$ as shown in Fig. 2. Namely, the 2nd linear mix-net transforms $\left\{U_{\mathrm{P}}(1), U_{\mathrm{P}}(1)^{\mathrm{R}}\right\}$ to $\left\{U_{\mathrm{P}}(1)^{(\mathrm{e} J)(\mathrm{ej}-1)--(\mathrm{ez}+1)}{ }_{\bmod \mathrm{B}}\right.$, $\left.U_{\mathrm{P}}(1)^{\mathrm{R}(\mathrm{eJ})(\mathrm{ej}-1)--(\mathrm{ez}+1)} \bmod \mathrm{B}\right\}=\left\{U_{\mathrm{P}}(1)^{\mathrm{e}^{*}} \bmod \mathrm{B}, U_{\mathrm{P}}(1)^{\mathrm{Re} *} \bmod \mathrm{B}\right\}$ by secret keys $\mathrm{e}_{\mathrm{J}},---, \mathrm{e}_{\mathrm{z}+1}$ of $S_{\mathrm{J}},---, S_{\mathrm{z}+1}$. Therefore, dishonest data registration record $\left\{U_{\mathrm{P}}(1), U_{\mathrm{P}}(1)^{\mathrm{R}}\right\}$ in the above must be replaced by $\left\{U_{\mathrm{P}}(1)^{\mathrm{e}^{*}}, U_{\mathrm{P}}(1)^{\operatorname{Re}^{*}}\right\}$.

Used seals solve also a problem, in which $P_{*}$ that conspires with $S$ and obtained $D=\left(\mathrm{T}_{\mathrm{P}}{ }^{\mathrm{W}} \mathrm{C}_{w}{ }^{\mathrm{W}}\right)^{\mathrm{XR}}$ that was calculated by $P$ impersonates $P$, the owner of credential $\mathrm{S}\left(\mathrm{d}_{1} \| \mathrm{d}_{2}, \mathrm{~T}_{\mathrm{P}}{ }^{\mathrm{R}+1} \mathrm{~K}_{\mathrm{w}} \mathrm{C}_{\mathrm{w}}{ }^{\mathrm{R}}\right)$. Namely, although $P *$ can know $\mathrm{S}\left(\mathrm{d}_{1} \| \mathrm{d}_{2}, \mathrm{~T}_{\mathrm{P}}^{\mathrm{R}+1} \mathrm{~K}_{\mathrm{w}} \mathrm{C}_{\mathrm{w}}{ }^{\mathrm{R}}\right){ }^{\mathrm{W}}$ and $D$ $=\left(\mathrm{T}_{\mathrm{P}}{ }^{\mathrm{W}} \mathrm{C}_{w}{ }^{\mathrm{W}}\right)^{\mathrm{XR}}$ after $P$ had used $\mathrm{S}\left(\mathrm{d}_{1} \| \mathrm{d}_{2}, \mathrm{~T}_{\mathrm{P}}{ }^{\mathrm{R}+1} \mathrm{~K}_{\mathrm{w}} \mathrm{C}_{\mathrm{w}}{ }^{\mathrm{R}}\right)^{\mathrm{W}}$, and $S$ and $P_{*}$ can jointly generate integers $\mathrm{X}^{*}$ and $\mathrm{W}^{*}$ so that $P_{*}$ can use $\mathrm{S}\left(\mathrm{d}, \mathrm{T}_{\mathrm{P}}^{\mathrm{R}+1} \mathrm{~K}_{1} \mathrm{~K}_{2}{ }^{\mathrm{R}}\right)^{\mathrm{WW}}$ while calculating $D^{\mathrm{W}^{*} \mathrm{X}^{*}}=$ $\left(\mathrm{T}_{\mathrm{P}}{ }^{\mathrm{W}} \mathrm{C}_{w}{ }^{\mathrm{W}}\right)^{\mathrm{XRW} \mathrm{X}^{*}}$ that is consistent with $\mathrm{R}$, either $P_{*}$ or $S$ that does not know R cannot calculate $U_{\mathrm{P} *}(\mathrm{~m})^{\mathrm{R}}(\mathrm{m}>\mathrm{n})$ consistently (here, it is assumed that $P$ had left used seals $U_{\mathrm{P}}(1)^{\mathrm{R}}, U_{\mathrm{P}}(2)^{\mathrm{R}},---$, $U_{\mathrm{P}}(\mathrm{n})^{\mathrm{R}}$ before). Although $P_{*}$ can leave $U_{\mathrm{P}}(\mathrm{n})^{\mathrm{R}}$ that $P$ had calculated before or inconsistent value $\underline{U}$ as its used seal, $S$ must reject $U_{\mathrm{P}}(\mathrm{n})^{\mathrm{R}}$ because it is shown repeatedly, also $S$ cannot impute the liability of this dishonesty by using $\underline{U}$ because it cannot identify $P$ from $\underline{U}$.

By exploiting used seals $S$ can also limit the numbers of times that members can use same credentials. Namely, in the credential verification procedure shown in Fig. $4, P$ is requested also to declare $n$, the number of times that it had used $\mathrm{S}\left(\mathrm{d}_{1 \|} \mathrm{d}_{2}, \mathrm{~T}_{\mathrm{P}}^{\mathrm{R}+1} \mathrm{~K}_{\mathrm{w}} \mathrm{C}_{\mathrm{w}}{ }^{\mathrm{R}}\right)$ before, and $S$ calculates used seal $U(\mathrm{n})^{\mathrm{R}}$, where $U(\mathrm{n})$ is an integer defined by $S$ and common to all members but unique to $\mathrm{n}$. Then, because $U(\mathrm{n})^{\mathrm{R}}$ is unique to pair $\{P, \mathrm{n}\}, S$ can reject excessively shown $\mathrm{S}\left(\mathrm{d}_{1} \| \mathrm{d}_{2}, \mathrm{~T}_{\mathrm{P}}{ }^{\mathrm{R}+1} \mathrm{~K}_{w} \mathrm{C}_{w}{ }^{\mathrm{R}}\right)$, i.e. $S$ memorizes pair $\left\{\mathrm{n}, U(\mathrm{n})^{\mathrm{R}}\right\}$ and rejects $P$ 's credential when $P$ declares a value more than the limit as $\mathrm{n}$ or when pair $\left\{\mathrm{n}, U(\mathrm{n})^{\mathrm{R}}\right\}$ had appeared already.

As the conclusion of this section, when compared with ZKP based anonymous credentials, which require numbers of interactive or non-interactive challenges and responses between $P$ and $S$, procedures in this section require $P$ to calculate only values $D=\left(\mathrm{T}_{\mathrm{P}}{ }^{\mathrm{W}} \mathrm{C}_{w}{ }^{\mathrm{W}}\right)^{\mathrm{XR}}, \quad A=U_{\mathrm{P}}(\mathrm{q})^{\mathrm{R}}$ and $B=$ $\left\{\left(U_{\mathrm{P}}(\mathrm{q}) \mathrm{T}_{\mathrm{P}}{ }^{\mathrm{W}} \mathrm{C}_{w}{ }^{\mathrm{W}}\right)^{\mathrm{XY}}\right\}^{\mathrm{R}}$. Therefore, anonymous tag based credentials enable developments of highly efficient data collection systems. Also, although all entities are required to carry out the dishonest entity identification procedure when dishonest events are detected, inconveniences caused by S's inquiries are mitigated if the procedures are included in payment processes for services.

\section{Protecting the SCHEME FROM OTHER Dishonesties}

As other kind of dishonest behaviors, member $P$ may put its data $D_{P}(q)$ with an encrypted number that cannot be decrypted to $\mathrm{N}_{\mathrm{P}}$. For example, when $P$ puts $\mathrm{D}_{\mathrm{P}}(\mathrm{q})$ with an encrypted number that is decrypted to $\mathrm{N}_{\mathrm{P} *}$ or to invalid value $\mathrm{N}_{\mathrm{X}}$, member $P *$ becomes the one that is responsible for actions corresponding to $\mathrm{D}_{\mathrm{P}}(\mathrm{q})$ or authority $S$ cannot correctly collect data from $P$. But, $S$ can easily detect this dishonesty as duplicated appearances of $\mathrm{N}_{\mathrm{P}^{*}}$ for $\mathrm{E}^{*}\left(\mathrm{k}_{\mathrm{Z}^{*}}, \mathrm{D}_{\mathrm{P}}(\mathrm{q})\right)$ and $\mathrm{E}^{*}\left(\mathrm{k}_{\mathrm{Z}^{*}}\right.$, $\left.\mathrm{D}_{\mathrm{P} *}(\mathrm{q})\right)$ in the $\mathrm{BB}$, or $\mathrm{E}^{*}\left(\mathrm{k}_{\mathrm{Z}^{*}}, \mathrm{D}_{\mathrm{P}}(\mathrm{q})\right)$ in the $\mathrm{BB}$ accompanied by invalid $\mathrm{N}_{\mathrm{X}}$. Also $P$ is identified as a liable member by using a credential attached to $\mathrm{E}^{*}\left(\mathrm{k}_{\mathrm{Z}^{*}}, \mathrm{D}_{\mathrm{P}}(\mathrm{q})\right)$.

\section{CONCLUSION}

A scheme for collecting data owned by anonymous entities and calculating their aggregate values while preserving privacies of individual entities is proposed. Although only summations were considered as aggregation operations, slight modifications of the scheme enable authorities to calculate also general polynomials of anonymous data [8]. In addition, computation volumes can be maintained as low as that for summations when the polynomial functions are not so complicated. Then, it becomes possible to use the scheme in various applications such as medical records processing in addition to those in e-governance and cloud computing systems.

\section{REFERENCES}

[1] W. Diffie and M. E. Hellman, "New Directions in Cryptography," IEEE Trans. On Information Theory, Vol. IT-22, No. 6, pp.644-654, 1976.

[2] D. Chaum, "Untraceable Electronic Mail, Return Address and Digital Pseudonyms," Communications of the ACM, vol. 24, no. 2, pp. 84-88, 1981.

[3] P. Golle and M. Jakobsson, "Reusable Anonymous Return Channels," Proc. of the 2003 ACM Workshop on Privacy in the Electronic Society, WPES '03, ACM, pp. 94-100, 2003.

[4] M. Belenkiy, J. Camenisch, M. Chase, M. Kohlweiss, A. Lysyanskaya and H. Shacham, "Randomizable Proofs and Delegatable Anonymous Credentials," Proc. of the 29th Annual International Cryptology Conference on Advances in Cryptology, pp. 108-125, August 2009.

[5] S. F. Shahandashti and R. Safavi-Naini, "Threshold Attributebased Signatures and their Application to Anonymous Credential Systems," Proc. of the 2nd International Conference on Cryptology in Africa: Progress in Cryptology, pp.198-216, 2009.

[6] S. Tamura and T. Yanase, "A Mechanism for Anonymous Credit Card Systems," IEEJ Trans. EIS, Vol. 127, No.1, pp.8187, 2007.

[7] S. Tamura, H. A. Haddad, K. Kouro, H. tsurugi, K. MD. R. Alam, T. Yanase and S. Taniguchi, "An Information System Platform for Anonymous Product Recycling," Journal of Software, Vol.3 No.3, pp.46-56, 2008.

[8] S. Tamura, "Anonymous Security Systems and Applications: Requirements and Solutions," Information Science Reference, 2012 